J. Lake Sci. (湖泊科学) , 2020, 32(4): 941-951

DOI 10. 18307/2020. 0404

(c) 2020 by Journal of Lake Sciences

\title{
城市富营养化湖泊的外源污染负荷与贡献解析一一以武汉市后官湖 为例
}

\author{
杨水化 ${ }^{1}$, 彭正洪 ${ }^{2}$, 焦洪赞 ${ }^{2}$, 许 静 $^{1}$, 王永桂 ${ }^{1 * *}$ \\ (1: 中国地质大学 (武汉) 地理与信息工程学院,流域关键带演化湖北省重点实验室,武汉 430074) \\ (2:武汉大学城市设计学院, 武汉 430079)
}

\begin{abstract}
摘 要: 为探究城市湖泊富营养化的污染负荷来源及其贡献率, 选择长江流域中下游典型富营养化湖泊 (武汉后官湖) 为 研究对象, 结合实测法、平均浓度法与排污系数法, 解析了后官湖的外部污染来源 (包括点源和面源, 面源又进一步划分 为农村生活、农业种植、水产养殖、畜禽养殖和城市径流). 结果表明: 化学需氧量 (COD) 主要来源于点源, 人湖贡献为 $54 \%$; 总磷主要来源于面源, 人湖贡献为 $71 \%$. 进一步笁选面源中污染物的主要来源发现, 总磷主要来自农业种植和水产 养殖, 人湖贡献分别为 $41 \%$ 和 $30 \%$; 面源中 COD 、氨氮和总氮贡献最大的是城市径流, 人湖贡献率分别为 $61 \% 、 53 \%$ 和 $37 \%$. 行政区污染排放贡献率中, COD、氨氮、总氮和总磷排放贡献率最大的分别为沌口街办 $(25.24 \%)$ 、蔡甸街办 $(23.28 \%)$ 、永丰街办 $(24.04 \%)$ 和大集街办 $(26.15 \%)$. 开展沌口街办和永丰街办的点源治理可有效消减人湖 COD 与氨氮 负荷,而大集街办的农业面源污染防治则是后官湖流域总磷治理的重点.
\end{abstract}

关键词: 富营养化湖泊;污染源负荷;贡献率;污染防控;后官湖

\section{External pollution source load and contribution of urban eutrophic lakes-Taking Lake Houguanhu of Wuhan as an example*}

\author{
YANG Shuihua $^{1}$, PENG Zhenghong ${ }^{2}$, JIAO Hongzan ${ }^{2}$, XU Jing $^{1}$ \& WANG Yonggui ${ }^{1 * *}$ \\ (1: Hubei Key Laboratory of Critical Zone Evolution, School of Geography and Information Engineering, China University of \\ Geosciences, Wuhan 430074, P.R.China) \\ (2: School of Urban Design of Wuhan University, Wuhan 430079, P.R.China)
}

\begin{abstract}
To explore the pollution sources and contribution rate of urban eutrophication lakes, a typical eutrophic lake (Lake Houguanhu in Wuhan) in the Yangtze River Basin was selected for research. With the field-measurement method, the mean-concentration method and the pollution-discharge-coefficient method, the external pollutant sources (including point source and nonpoint source) of Lake Houguanhu was analyzed. Non-point sources (NPS) were further divided into several source types, such as the pollutants from the rural life, the agricultural planting, the aquaculture, the livestock, the poultry farming and the urban runoff. Results show that the COD in Lake Houguanhu is mainly from the point source with a contribution rate of 54\%, total phosphorus is mainly from the non-point sources with a rate of $71 \%$. Further exploring the main non-point sources, it is found that the total phosphorus is mainly from the agricultural planting and aquaculture, with the contribution rates of $41 \%$ and $30 \%$, respectively. The largest contribution of COD, ammonia nitrogen and total nitrogen in NPS is urban runoff, with contribution rates of $61 \%, 53 \%$ and $37 \%$, respectively. For administrative districts, the highest contribution rates of COD, ammonia nitrogen, total nitrogen and total phosphorus emissions are Zhuankou Street Office (25.24\%), Caidian Street Office (23.28\%), Yongfeng Street Office (24.04\%) and Daji Street Office (26.15\%). Results indicated that, with point source treatment of the Zhuankou Street and the Yongfeng Street, the COD and ammonia nitrogen loads can be effectively reduced. The agricultural non-point source pollution prevention and control of Daji Street is the focus of total phosphorus management in Lake Houguanhu Basin.
\end{abstract}

\footnotetext{
* 2019-05-27 收稿; 2019-11-24 收修改稿. 国家自然科学基金项目 (41807471) 资助.

** 通信作者;E-mail : wangyg@ cug.edu.cn.
} 
Keywords: Eutrophic lake; pollution source loads; contribution rates; pollution prevention and control; Lake Houguanhu

解析湖泊污染物的主要来源及其负荷贡献, 对揭示湖泊富营养化和污染效应、开展“一湖一策”治理具 有重要的作用 ${ }^{[1]}$. 近年来, 围绕水体污染物种类和来源、污染物产生和排放情况的调查工作大量开展 ${ }^{[2-4]}$; 但 从湖泊流域的角度、行政区域管理的视角精细解析湖泊污染源相关工作仍少有报导.

武汉地处长江中游城市群核心, 是长江经济带的重要城市,在长江流域生态安全格局、经济社会发展、 长江文明传承创新中发挥着重要枢纽作用 ${ }^{[5]}$. 武汉因水而兴, 在武汉市诸多湖泊中, 后官湖是重要的战略水 源地, 其在武汉市的发展中有着重要的支撑作用, 但随着湖区周围人口、工农业生产的快速增长和大规模经 济开发, 污染物的排放量增大, 导致湖泊生态环境面临着水质恶化、水体富营养化、水生态风险加剧等诸多 全国湖泊所共有的生态问题 ${ }^{[6]}$. 解析污染来源, 是后官湖治理的关键也是难题. 部分学者采用实测的方式, 核算了后官湖周边的污染物来源, 提出了后官湖流域污染的控制对策, 具有一定的借鉴意义 ${ }^{[7]}$. 但后官湖由 4 个子湖组成、流域范围内水系较为复杂, 且覆盖了武汉市的三区八街办, 其污染来源既有来自工业和污水 处理厂的点源、又有流域内农村生活生产的面源, 仅通过实测方式无法全面的解析后官湖的污染来源、更无 法确定不同行政区的污染贡献. 本文采用实测法与经验公式法相结合的量化方法,核算了后官湖流域的污 染人湖量,并解析了不同污染源、不同行政区的污染负荷量和贡献率.

\section{1 研究区概况与方法}

\section{1 后官湖流域概况}

后官湖位于湖北省武汉市 $\left(30^{\circ} 28^{\prime} \sim 30^{\circ} 33^{\prime} \mathrm{N}, 114^{\circ} 0^{\prime} \sim 114^{\circ} 8^{\prime} \mathrm{E}\right)$, 处于蔡甸区、武汉市三环线与绕城公路 之间, 是蔡甸区境内第一大湖泊, 由高湖、白莲湖 (皮泗海)、南湖 (知音湖)、天鹅湖 (后官湖) 组成. 后官湖规 划保护水域面积 $40.81 \mathrm{~km}^{2}$, 岸线长度 $194.3 \mathrm{~km}$, 汇水面积约 $222.42 \mathrm{~km}^{2}$, 区域平均气温 $16.5^{\circ} \mathrm{C}$, 降雨集中于 5-8 月份, 年平均降雨量 $1236 \mathrm{~mm}$. 流域范围内包括有蔡甸区、汉阳区和武汉经济技术开发区 (经开区), 内 辖蔡甸区的张湾街办、王贤街办、蔡甸街办、参山街办、大集街办, 武汉经开区沌口街办和汉阳区的永丰街办 等街办 (图 1a).

后官湖属于保留区, 水质目标为 III类水体, 是集中式生活饮用水源地二级保护区. 根据武汉市水务局的 监测数据 (2013-2017 年), 计算并分析后官湖各湖水质监测指标的变化趋势和水质类别, 结果显示. 近五 年来, 后官湖全湖水质由 III 类转向 IV 类, 呈现水质类别降低的趋势, 主要超标因子为总氮和总磷, 如图 $1 \mathrm{~b}$ 所 示; 富营养化由轻营养化向中营养化转变, 局部区域为富营养化状态. 2016 年是后官湖水质超标的转折年 份, 因此本文选择 2016 年调查和监测获得的相关数据进行后官湖的污染源解析, 以探讨影响其水质恶化的
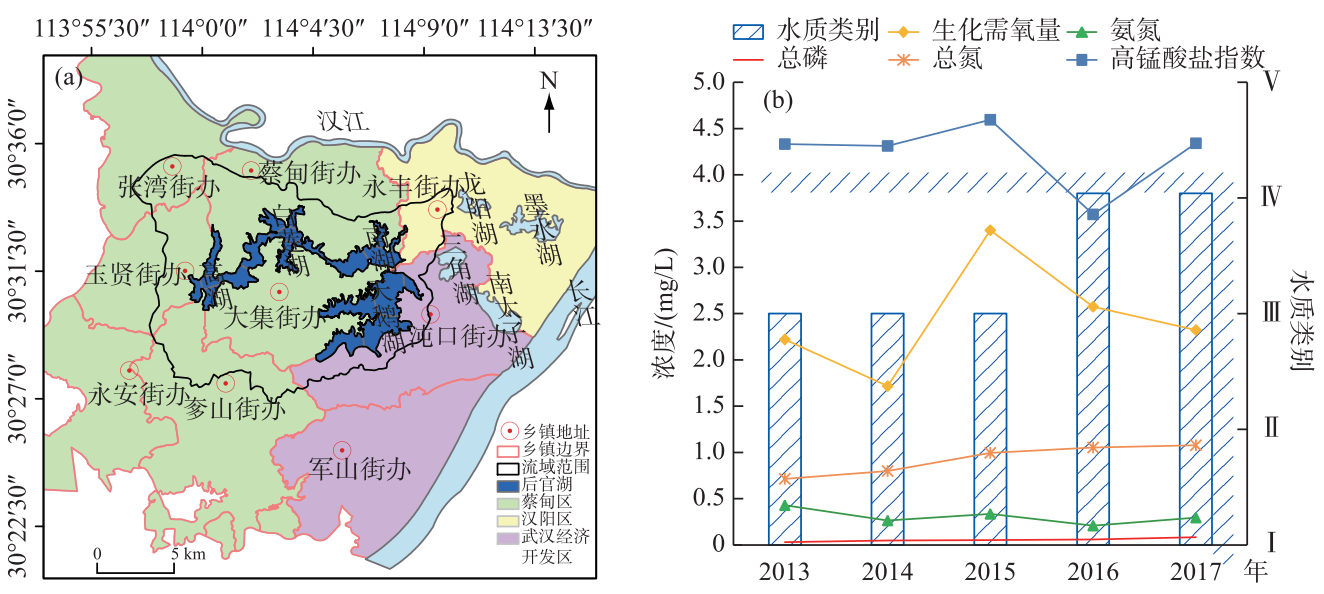

图 1 后官湖区域位置和流域行政区划 (a) 和水质变化(2013-2017 年) (b)

Fig.1 Lake Houguanhu regional location and administrative division( a), its water quality (from 2013 to 2017) (b) 


\section{主要因子.}

\section{2 研究方法}

国内外常用的污染物排放核算方法有排污系数法 ${ }^{[8-9]}$ 、输出系数法 ${ }^{[10-11]}$ 、平均浓度法 ${ }^{[12]}$ 和实测法等 ${ }^{[13]}$. 前三者属于经验公式法,其中排污系数法和输出系数法适用于实测资料缺乏的面源核算; 平均浓度法适用 于有少量实测的面源核算; 实测法适用于点源 (排污口) 排放核算. 本文中,采用实测法监测后官湖周边工业 污染源、城镇污水处理厂等稳定排放口的污染物排放量; 部分未经集中收集和处理的污水渠道为非稳定排 放, 如城市地表径流, 这部分污染通过实测法测得一定时间内的污染物浓度与流量, 再经平均浓度法估算全 年排放量; 同时, 后官湖流域内, 存在诸多的村庄、有一定规模的农村养殖业和农业生产, 这些污染源的排放 具有典型的面源性质,通过排污系数法进行核算,计算方法如图 2 所示.

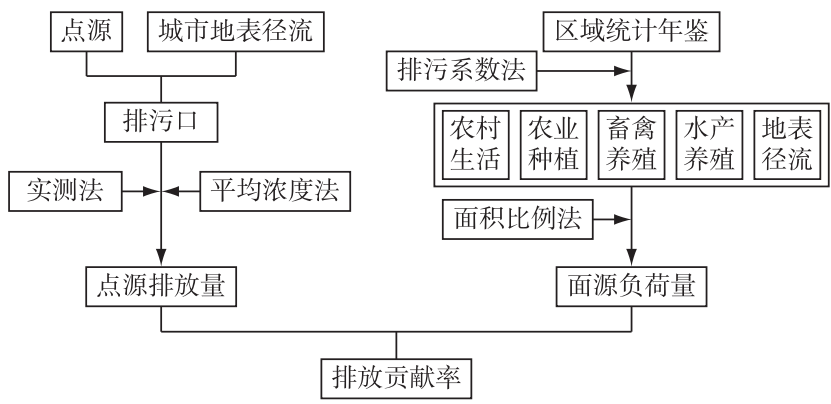

图 2 后官湖流域污染源排放量核算与贡献率计算方法

Fig.2 Calculation method for contribution rate of watershed pollution source emissions in Lake Houguanhu Basin

后官湖的人湖污染中, 点源主要来源于工业点源和城镇生活污水处理厂排放 ${ }^{[14]}$, 其余未经污水处理厂 收集的城镇区域生活源,通过径流管网排人人湖河道汇人后官湖;面源包括农村生活、畜禽养殖、农业生产 和水产养殖. 点源与城市地表径流分别通过 2016 年的排污口实地调查、监测及计算获得, 面源基于 2016 年 的蔡甸区、武汉市经济开发区、汉阳区统计年鉴, 采用排污系数法 ${ }^{[15-16]}$ (表 1) 得到各区域的面源排放量,再利 用面积比例法核算得到后官湖流域范围内的不同种类面源排放量. 公式计算获得的污染负荷量为化学需氧 量 $(C O D)$ 、氨氮、总磷、总氮等水质指标各自的年负荷总量.

表 1 排污系数法计算公式

Tab.1 Calculation equations of discharge coefficient method

\begin{tabular}{|c|c|c|c|}
\hline 污染源 & 公式 & 符号及单位 & 备注 \\
\hline 农村生活 & $G_{\mathrm{p}}=365 \mathrm{~N} \cdot S_{\mathrm{p}} \times 10^{-10}$ & $\begin{array}{l}G_{\mathrm{p}} \text { 为某种污染排放量 }(\text { 万 } \mathrm{t} / \mathrm{a}) ; N \text { 为常住人口数 }(\text { 人 }) ; \\
S_{\mathrm{p}} \text { 为污染物排放系数 }(\mathrm{g} /(\mathrm{d} \cdot \text { 人) })\end{array}$ & \multirow{4}{*}{$\begin{array}{l}\text { COD、总氮、总 } \\
\text { 磷和氨氮的污 } \\
\text { 染负荷均采用 } \\
\text { 同一公式计算 }\end{array}$} \\
\hline 农业种植 & $P=\sum\left(A_{\mathrm{N}} \cdot F_{\mathrm{N}}+A_{\mathrm{P}} \cdot F_{\mathrm{P}}\right) / 10^{4}$ & $\begin{array}{l}P \text { 为某种污染物负荷量 }(\text { 万 } \mathrm{t} / \mathrm{a}) ; A_{\mathrm{N}} 、 A_{\mathrm{P}} \text { 为农田氮肥、磷 } \\
\text { 肥施用量 }(\mathrm{t} / \mathrm{a}) ; F_{\mathrm{N}} 、 F_{\mathrm{P}} \text { 为氮肥、磷肥的流失系数 }(\%)\end{array}$ & \\
\hline 畜禽养殖 & $M=\sum C_{i} \cdot P_{i} \times 365 / 10^{7}$ & $\begin{array}{l}M \text { 为某种污染物排放量 }(\text { 万 } \mathrm{t} / \mathrm{a}) ; C_{i} \text { 为第 } i \text { 种禽兽总数 } \\
(\text { 头 }) ; P_{i} \text { 为第 } i \text { 种禽兽排放系数 }(\mathrm{kg} /(\text { 头 }(\text { 只 }) \cdot \mathrm{d}))\end{array}$ & \\
\hline 地表径流 & $P=A \cdot u \cdot \lambda$ & $\begin{array}{l}P \text { 为某种污染物排放量 }(\mathrm{t} / \mathrm{a})) ; A \text { 为城市面积 }\left(\mathrm{km}^{2}\right) ; u \\
\text { 为标准源强系数 }\left(\mathrm{t} /\left(\mathrm{a} \cdot \mathrm{km}^{2}\right)\right) ; \lambda \text { 为修正系数 }\end{array}$ & \\
\hline 水产养殖 & $\begin{array}{l}M_{\mathrm{N}}=\left(C \cdot f_{\mathrm{N}}-b_{\mathrm{N}}\right) \times 10^{3} \\
M_{\mathrm{P}}=\left(C \cdot f_{\mathrm{P}}-b_{\mathrm{P}}\right) \times 10^{3}\end{array}$ & $\begin{array}{l}M_{\mathrm{N}} 、 M_{\mathrm{P}} \text { 分别表示氮负荷量 }(\mathrm{kg}) \text { 和磷负荷量 }(\mathrm{t}) ; C \text { 为饵 } \\
\text { 料系数; } f_{\mathrm{N}} f_{\mathrm{P}} \text { 分别为饵料中的氮、磷含量百分比; } b_{\mathrm{N}} 、 b_{\mathrm{P}} \\
\text { 分别为养殖生物体内氮和磷的含量百分比 }\end{array}$ & $\begin{array}{l}\text { 适用于总氮、总 } \\
\text { 磷的污染负荷 } \\
\text { 计算 }^{[17-18]}\end{array}$ \\
\hline
\end{tabular}


发展水平等因素依照不同类别确定排污系数. 如农村生活排污系数参考《村镇生活污染防治最佳可行技术 指南 (试行) (HJ-BAT-9)》; 畜禽养殖源参照《第一次全国污染源普查畜禽养殖业源产排污系数手册》中猪的 排放量核定, 其中 30 只蛋鸡折合为 1 头猪, 60 只肉鸡折合为 1 头猪, 3 只羊折合为 1 头猪, 1 头牛折合为 5 头 猪; 水产养殖源参照《第一次全国污染源普查水产养殖业污染源产排污系数手册》确定排污系数法核算其染 排放量; 农业种植源肥料流失系数参考《第一次全国污染源普查农业污染源肥料流失系数手册》. 在此基础 上,计算得到污染物排放量; 然后选择能明显区分出不同面源来源的人湖口进行污染负荷实测得到实际人 河量, 实际人河量除以计算污染排放量得到人河系数, 再参考相关研究 ${ }^{[24]}$ 人湖系数的研究成果, 确定后官湖 流域不同污染源的平均人湖系数,如表 2 所示.

表 2 不同污染源人湖系数*

Tab.2 Coefficients of different pollution sources into lake

\begin{tabular}{cccccc}
\hline 污染源 & 参数 & COD & 总氮 & 总磷 & 氨氮 \\
\hline 农村生活 & $S_{\mathrm{p}} /(\mathrm{g} /(\mathrm{d} \cdot$ 人 $))$ & 40.00 & 5.00 & 0.44 & 4.00 \\
& 人湖系数 & 0.20 & 0.10 & 0.05 & 0.10 \\
农业种植 & $F_{\mathrm{N}}$ 和 $F_{\mathrm{p}} / \%$ & 0.00 & 1.85 & 1.55 & 1.35 \\
& 人湖系数 & 0.20 & 0.10 & 0.05 & 0.10 \\
畜禽养殖 & $P_{i} /(\mathrm{g} /($ 头 $\cdot \mathrm{d}))$ & 133.70 & 22.69 & 8.45 & 10.72 \\
& 人湖系数 & 0.22 & 0.15 & 0.10 & 0.15 \\
地表径流 & $u /\left(\mathrm{t} /\left(\mathrm{a} \cdot \mathrm{km}^{2}\right)\right)$ & 50.00 & 5.00 & 1.00 & 8.00 \\
& 人湖系数 & 0.24 & 0.15 & 0.10 & 0.20 \\
\hline 水产养殖 & 饵料系数 $C$ & $f_{\mathrm{N}}$ & $f_{\mathrm{P}}$ & $b_{\mathrm{P}}$ & $b_{\mathrm{N}}$ \\
& 0.70 & $2.50 \%$ & $0.40 \%$ & $0.63 \%$ & $2.86 \%$ \\
\hline
\end{tabular}

* 水产养殖不同污染源的入湖系数均为 0.6 .

统计年鉴得到的是整个街道的人口、农业生产和社会经济等数据, 但由于流域边界与行政区边界并不 完全重合 (图 1a). 因此,计算过程中, 首先通过水文分析, 得到后官湖的流域范围, 然后根据水文分区与行 政区的空间关系,采用面积比例法获得流域内街道面积所占总街道面积的比值,再利用该比值计算得到流 域内各街道办的面源排放量, 再利用人湖系数, 得到不同污染源的人湖总量. 本文采用的面积比例法, 是在 假定同一个行政区, 其人口分布密度、耕地密度等平均分布的条件下进行的, 该方法仅适用于乡镇、街道办 等面积较小的行政区,对于人口、耕地等空间分异性较大的城市,该方法并不适用.

\section{2 结果与分析}

\section{1 点源污染源解析}

基于后官湖周边环保等部门的调查实测结果及国家《污水综合排放标准》(GB 8978-1996) 中污染物的 排放浓度标准, 到 2015 年底, 后官湖蔡甸区的排污口中分别有 11 个污染物排放浓度未达标排口和 7 个已达 标排口,2016 年新增 3 个排污口; 汉阳区仅 1 个排污口且未达标; 武汉经济开发区 8 个排污口未接人市政污 水管网,均未达标, 2016 年新增 14 个排污口. 将 2016 年后官湖流域周边的这些点源按照污水排口、混流排 口和雨水排口进行区分, 得到后官湖周边点源的空间分布 (图 3).

后官湖周边 2016 年共有 44 个点源排放口, 其中 1 个位于汉阳区、21 个位于蔡甸区、22 个位于经开区 (表 3), 根据后官湖周边环保部门 2016 年的污染排放口实测监测数据, 3 个区域的污染物人湖量如表 3 所示.

从排污口的数量分布来看, 武汉经济开发区和蔡甸区是后官湖的主要点源排放区. 但从排放量来看, 后 官湖流域点源污染中, 3 个区排口的 COD 排放量相差不大; 氨氮、总氮和总磷, 则以蔡甸区排口和汉阳区排 口为主, 其中, 蔡甸区排口 COD、氨氮、总氮和总磷的污染负荷贡献分别为 $33.19 \% 、 40.83 \% 、 34.57 \%$ 和 $42.72 \%$; 汉阳区 COD、氨氮、总氮和总磷的主要污染物贡献分别为 $30.40 \% 、 41.54 \% 、 50.02 \%$ 和 $41.54 \%$. 从以 上区域的点源污染贡献率来看, 后官湖流域治理点源污染, 首先要重视汉阳区人湖排污口的治理, 该排污口 
污染负荷大, 是后官湖点源中的主要污染源; 其次, 经开区排污口和蔡甸区排口数量多, 存在排污口叠加等 多种问题. 细小排污口的混乱、不规则和叠加设定, 增加了湖泊污染治理难度和成本, 在后官湖的污染治理 中, 首先需要集中对蔡甸区和经开区的排污口进行整治, 清理小排污口, 建立排污口监控制度, 严格杜绝周 边排污口的违规排放.

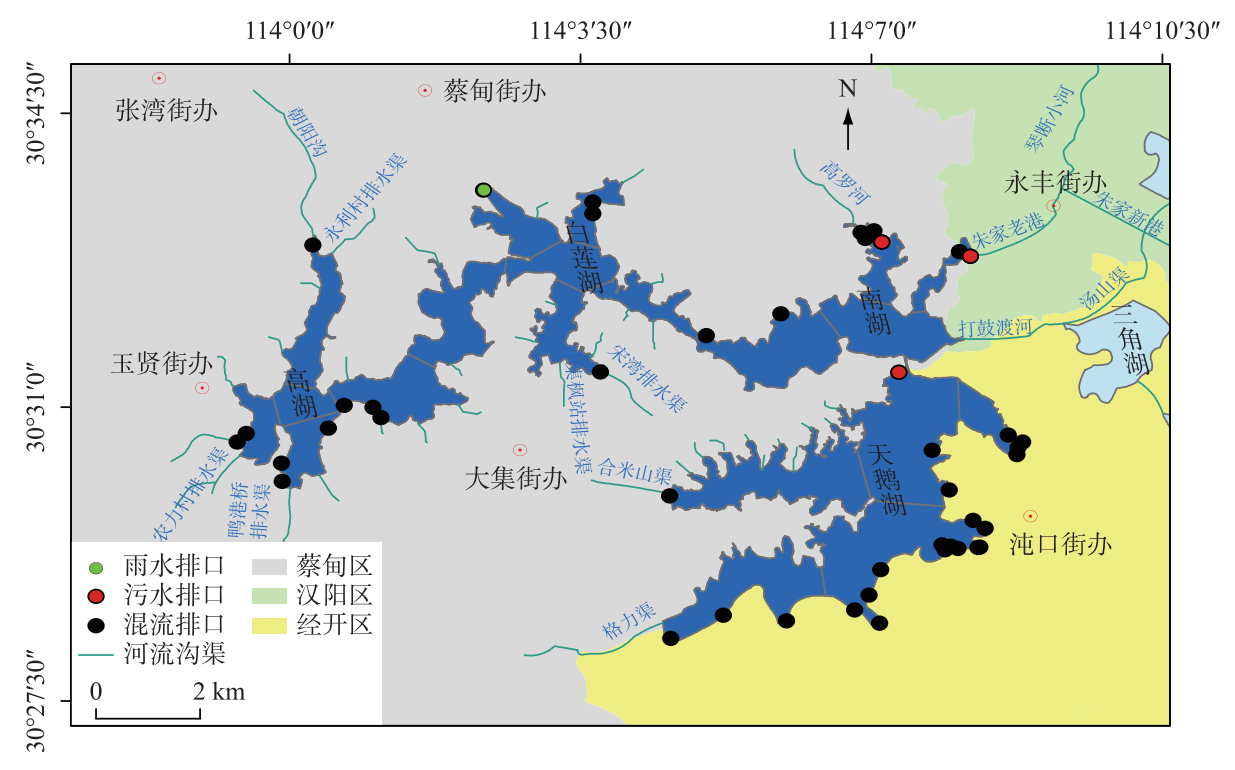

图 3 后官湖沿湖排污口分布

Fig.3 Distribution of pollutions sources outlets along the Lake Houguanhu

表 3 后官湖流域排口人湖污染量

Tab.3 The amount of outlets into the lake in Lake Houguanhu Basin

\begin{tabular}{cccccc}
\hline \multirow{2}{*}{ 排污口名称 } & \multirow{2}{*}{ 排污口数量 } & \multicolumn{4}{c}{ 污染物人湖量 $/(\mathrm{t} / \mathrm{a})$} \\
\cline { 3 - 6 } & & COD & 氨氮 & 总氮 & 总磷 \\
\hline 汉阳区 & 1 & 722.70 & 81.76 & 146.00 & 10.59 \\
蔡甸区 & 21 & 789.11 & 80.36 & 100.90 & 10.89 \\
经开区 & 22 & 865.52 & 34.72 & 44.98 & 4.01 \\
合计 & 44 & 2377.33 & 196.84 & 291.88 & 25.49 \\
\hline
\end{tabular}

\section{2 面源污染源解析}

2.2.1 不同类型面源污染贡献率 农村生活、农业种植、畜禽养殖、水产养殖和城市地表径流是后官湖周边的 主要面源来源,采用不同污染源排放量所占总面源排放量的比值,得到不同面源种类的排放贡献率(图 4).

从图 4 中看出, COD 和氨氮负荷最大的均为城市地表径流, 分别占污染物总排放量的 61\%、53\%. 这源 于近年后官湖周边发展快, 城镇建设改变了周边道路、土地利用方式, 使下垫面发生变化, 降低了陆地的雨 污收纳控制能力, 使得城市地表径流污染增加 ${ }^{[25-26]}$. 此外通过分析后官湖流域土地利用格局, 发现区域内人 口和工农业活动多集中在湖泊周边地区, 废污水收集处理率较低,给后官湖的水质带来重要的影响, 因此开 展雨污分流、提高雨水径流的收集和湖区周边污染物的处理,有利于后官湖 COD、氨氮的消减工作. 然而, COD、氨氮污染负荷并不是后官湖最突出的问题, 总磷和总氮超标才是引起后官湖水质超标的主要原因. 从 图 4 中看出, 总氮负荷最大的是城市地表径流源, 占比 $37 \%$, 水产养殖次之 $(29 \%)$. 总磷负荷最大的是农业 种植, 占比 $41 \%$, 水产养殖次之 $(30 \%)$. 当前形势下, 农田种植和养殖是大部分区域总磷负荷的主要贡献源, 存在治理难度大、控源成本高等问题 ${ }^{[27-28]}$. 后官湖流域的水产养殖和农业种植对总氮与总磷具有较大的贡 


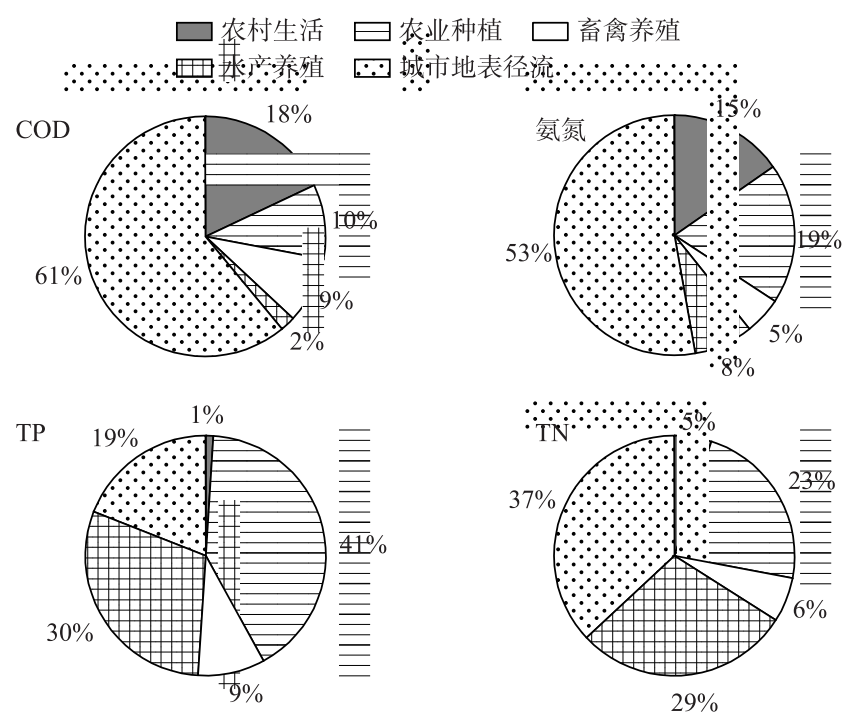

图 4 面源中不同污染源排放贡献率

Fig.4 Contribution rate of different pollution sources in non-point source

献,成为造成后官湖水质恶化和超标的主要原因. 调查发现, 湖泊局部流域仍存在集约化水产养殖, 水产养 殖采用直接投食投肥的养殖方式, 增加了湖区的氮、磷污染负荷. 因此开展生态农业和严格执行后官湖的限 养、禁养措施, 显得极其迫切. 在后官湖西部, 除农业种植产生的农药化肥流失外, 大量莲藕、菱等水生经济 作物的种植也增加了氮、磷的污染风险.

2.2.2 不同行政区污染贡献率 将面源污染分配到 3 个区域的不同街办, 得到后官湖周边各街办面源的 COD 、总氮、总磷、氨氮污染贡献率(图 5).

在后官湖周边 8 个街办中, $\mathrm{COD}$ 、氨氮和总氮的主要来源是城市地表径流, 对城市地表径流的贡献中, 三 者都表现出相同的规律, 比重最大的是大集街办, 其次为蔡甸街办, 二者占比超过了 $50 \%$. 从图 1a 可知, 后 官湖流域中, 大集街办和蔡甸街办辖区范围大, 地表径流受纳面积相对较大, 径流污染物产生较多; 再者, 两 街办均处于蔡甸区, 近年来蔡甸区积极建设中法生态城、环湖绿道, 相关建设增加了土地利用硬化程度, 有 利于地表汇流, 但当地排水设施老旧, 使得大部分污染物随径流流人湖泊. COD 贡献中, 农村生活源是面源 的第二大污染源, 对农村生活源贡献最大的街办为沌口街办、其次为大集街办和蔡甸街办, 三者的占比均超 过了 $20 \%$. 这部分街办在农业人口上占有较大比重, 人口活动密布, 分散着大量农业人口, 农村生活污染非 常普遍,生活垃圾堆放问题也常见,产生的污染物自然增多. 氨氮的第二大污染源为农业种植, 张湾街办所 占比例最大, 其次为大集街办. 总磷的主要来源为农业种植, 以张湾街办和大集街办所占的比例最大, 二者 所占比例在 $23 \%$ 以上, 其次为玉贤街办. 张湾街办和大集街办的农业仍以传统农耕为主, 精耕细作且大量地 施用复合肥, 使得未被完全吸收的肥料极易被雨水冲刷带人后官湖, 成为湖区总磷的重要来源. 总氮的第二 大污染源为水产养殖, 以大集街办所占比例最大. 该区域湖岸线较长, 养殖管理难度大, 养殖人员生活废污 水的直排、饵料沉降、排泄物得不到及时收集和清除,造成湖泊总氮污染.

不同街办所占不同类型污染源的贡献表明,开展后官湖面源的治理中, 针对 COD 、氨氮、总磷、总氮应该 采取不同的策略,分别以不同的街办为重点进行治理和防控.

\section{3 后官湖流域污染源负荷贡献率}

2.3.1 点面源总污染贡献 实测和计算得到如表 4 所示的人湖总量, 2016 年后官湖流域点、面源污染中, COD 、氨氮、总氮和总磷的人湖总量分别为 $4397.96 、 429.98 、 694.37$ 和 $89.41 \mathrm{t} / \mathrm{a}$. 


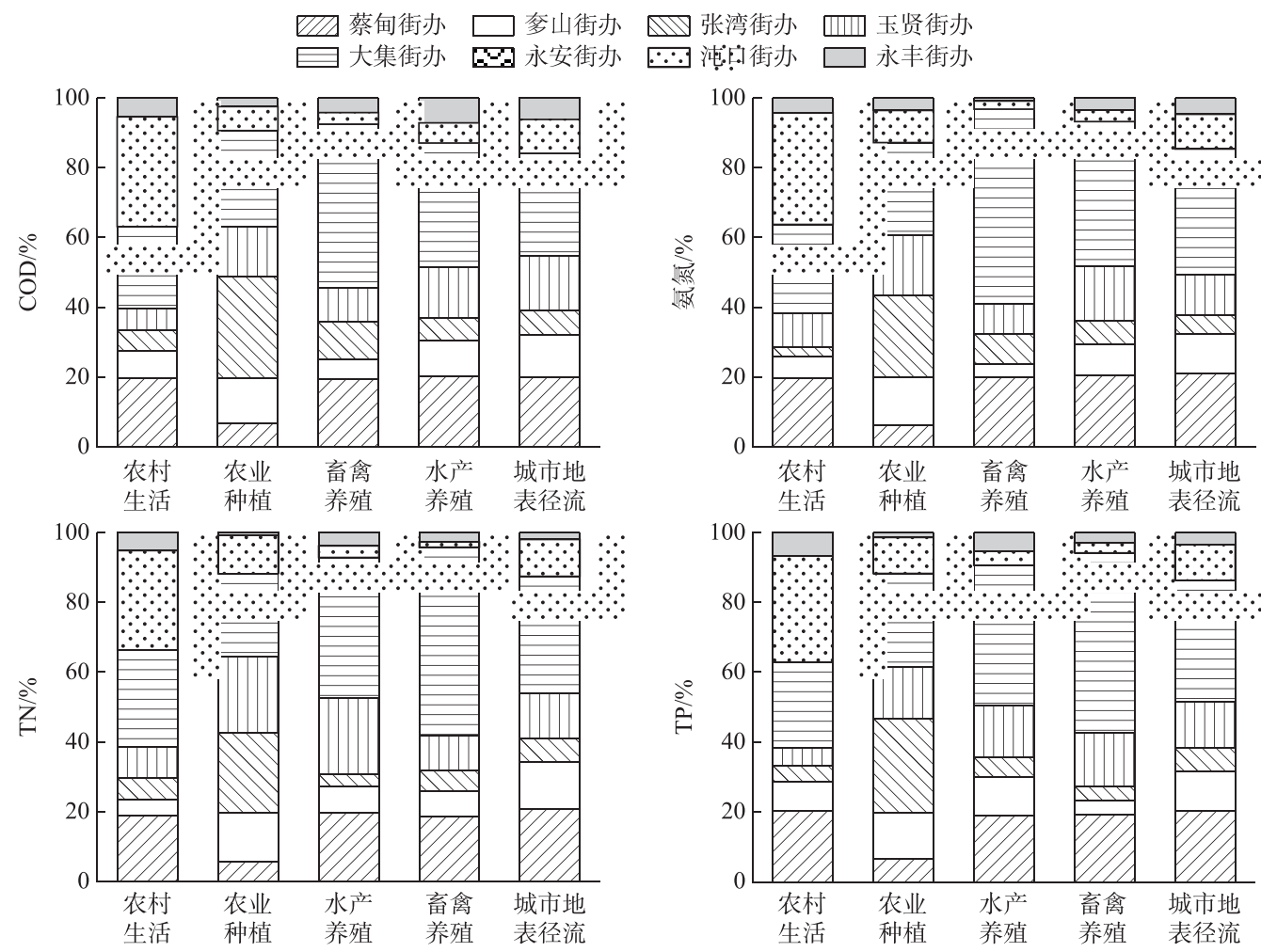

图 5 不同街办不同面源污染贡献率

Fig.5 Different non-point source pollution contribution rates of different street offices

表 4 后官湖污染源人湖总量

Tab.4 Total amount of pollution into the Lake Houguanhu

\begin{tabular}{ccccc}
\hline 项目 & COD/ $(\mathrm{t} / \mathrm{a})$ & 氨氮 $/(\mathrm{t} / \mathrm{a})$ & 总氮 $/(\mathrm{t} / \mathrm{a})$ & 总磷/ $(\mathrm{t} / \mathrm{a})$ \\
\hline 点源 & 2377.33 & 196.84 & 291.88 & 25.49 \\
面源 & 2020.63 & 233.14 & 402.49 & 63.92 \\
合计 & 4397.96 & 429.98 & 694.37 & 89.41 \\
面源占比 & $46 \%$ & $54 \%$ & $58 \%$ & $71 \%$ \\
\hline
\end{tabular}

后官湖流域中, COD、氨氮和总氮的排放贡献中, 点面源差别不大. 其中, 点源占 COD 总排放的 $54 \%$, 大 于面源; 但面源的氨氮和总氮排放占比分别为 54\% 和 $58 \%$, 大于点源. 而总磷则以面源贡献为主, 占比达到 了 $71 \%$. 排放总量结果表示, 进行后官湖流域的污染治理, 不仅要严格控制点源污染、更要加强对面源的污 染防控.

2.3.2 不同行政区总污染贡献 将点源和面源的污染排放统计到不同街办, 得到如后官湖流域不同街办的 COD 、氨氮、总氮和总磷污染排放空间分布 (图 6).

后官湖流域的 COD、氨氮、总氮和总磷的排放具有明显的空间分异性, 其中 COD 的排放以后官湖东南 角的沌口街办为主; 氨氮以蔡甸街办为主, 永丰街办次之. 总氮的排放, 以永丰街办和大集街办为主; 总磷的 排放, 主要集中在大集街办. 由于每个乡镇的产业不一致,产生的污染物呈现出空间异质性特征, 沌口街办 地表相对破碎化, 随径流产生的 COD 较多; 大集街办在农业种植和水产养殖方面具有地理优势, 因此以排放 含氮、磷等污染物较多,不同街办污染排放总量的贡献如表 5 . 

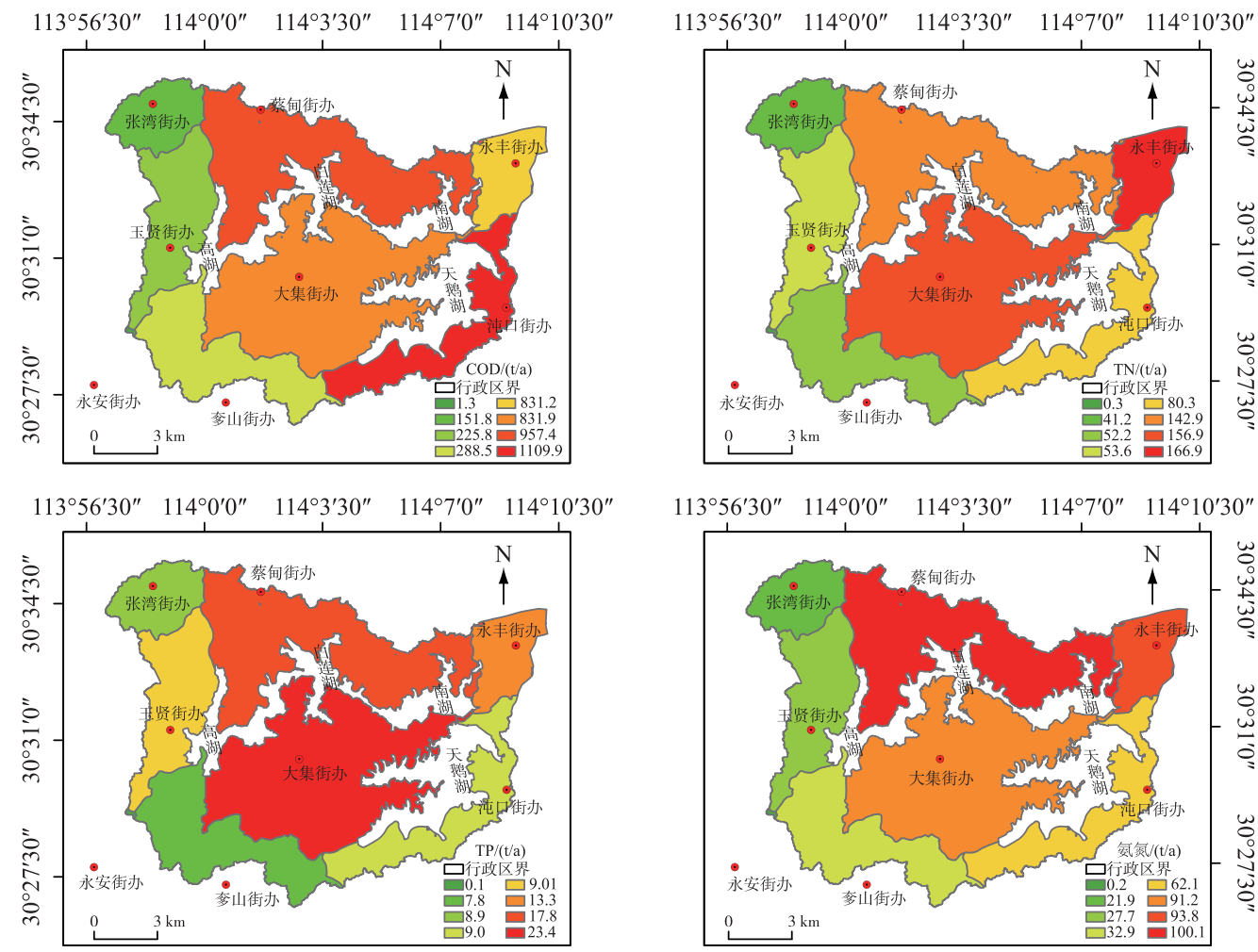

图 6 后官湖流域不同街办污染排放空间分布

Fig.6 Spatial distribution of pollution discharge in different street offices in Lake Houguanhu Basin

表 5 后官湖不同街办污染排放量和贡献率

Tab.5 Pollution discharge and contribution rate of different street offices in Lake Houguanhu

\begin{tabular}{|c|c|c|c|c|c|c|c|c|}
\hline \multirow{2}{*}{ 乡镇街办 } & \multicolumn{4}{|c|}{ 排放量/(t/a) } & \multicolumn{4}{|c|}{ 贡献率/\% } \\
\hline & COD & 氨氮 & 总氮 & 总磷 & COD & 氨氮 & 总氮 & 总磷 \\
\hline 蔡甸街办 & 957.39 & 100.10 & 142.95 & 17.77 & 21.77 & 23.28 & 20.59 & 19.87 \\
\hline 萝山街办 & 288.53 & 32.93 & 52.20 & 7.80 & 6.56 & 7.66 & 7.52 & 8.72 \\
\hline 张湾街办 & 151.84 & 21.93 & 41.19 & 8.96 & 3.45 & 5.10 & 5.93 & 10.02 \\
\hline 玉贤街办 & 225.79 & 27.74 & 53.62 & 9.07 & 5.13 & 6.45 & 7.72 & 10.14 \\
\hline 大集街办 & 831.96 & 91.19 & 156.86 & 23.38 & 18.92 & 21.21 & 22.59 & 26.15 \\
\hline 永安街办 & 1.32 & 0.18 & 0.34 & 0.07 & 0.03 & 0.04 & 0.05 & 0.07 \\
\hline 沌口街办 & 1109.95 & 62.09 & 80.29 & 9.05 & 25.24 & 14.44 & 11.56 & 10.12 \\
\hline 永丰街办 & 831.20 & 93.82 & 166.91 & 13.33 & 18.90 & 21.82 & 24.04 & 14.91 \\
\hline
\end{tabular}

由表 5 可知,在 COD 的主要污染排放贡献中,沌口街办、蔡甸街办和大集街办各贡献 $25.24 \% 、 21.77 \%$ 和 $18.92 \%$ ，三者之和占总 COD 排放的 $65.92 \%$; 汉阳区的永丰街办占 COD 的 $18.9 \%$. 这是因为后官湖的 COD 主要来源于排污口、城市地表径流和农村生活污水, 这些区域为后官湖周边主要的人口聚居区, 土地硬化程 度高、生活污染排放量大, 因此控制 COD 需要严格开展这些街办的生活污水的治理, 提高污水管网的收集率 和处理率. 氨氮的污染贡献中, 贡献占比排名前三的蔡甸街办、永丰街办和大集街办, 占比分别为 $23.28 \%$ 、 $21.82 \%$ 和 $21.21 \%$. 总氮的污染贡献中, 贡献占比排名前三的为永丰街办 大集街办和蔡甸街办, 占比分别为 $24.04 \%$ 、22.59\% 和 $20.59 \%$ 。总磷主要来自于大集街办和蔡甸街办, 各占 $26.15 \%$ 和 $19.87 \%$, 其余街办总磷排 
放相对较为均匀. 农业种植是总磷的最大贡献污染源 ${ }^{[14]}$, 沿后官湖的大集街办和蔡甸街办还存在较为密集 的农业种植区, 在对后官湖总磷的治理中, 需要重点关注大集街办和蔡甸街办的农业种植污染, 从生态农 业、施肥管理等方面进行整治.

\section{3 结论和展望}

\section{1 结论}

本文选择典型富营养化湖泊武汉市后官湖为研究对象, 解析了 2016 年后官湖 COD、氨氮、总磷和总氮 的主要污染负荷来源. 结果发现,2016 年,后官湖的 COD 和氨氮主要来自于点源污染负荷,贡献率为 $54 \%$; 总磷主要来自于面源, 贡献率为 $71 \%$, 其中农业种植和水产养殖分别占比为 $41 \%$ 和 $30 \%$. 为探寻城市湖泊污 染的责任主体,本文分析了不同行政区域对后官湖的污染贡献,结果表明 COD、氨氮、总氮和总磷排放贡献 率最大的分别为沌口街办、蔡甸街办、永丰街办和大集街办, 贡献分别为 $25.24 \% 、 23.28 \% 、 24.04 \%$ 和 $26.15 \%$. 因此, 开展后官湖的污染防治, 需重点关注沌口街办点源排放带来的 COD, 以及大集街办的种植业和养殖业 带来的总磷污染.

\section{2 展望}

本文选择的方法, 简单便于操作, 资料的获取相对容易, 能从宏观层面揭示水体污染物的主要来源及其 贡献, 对同类型湖泊的源解析和污染防控有着一定的借鉴意义. 但采用排污系数法和人湖系数法进行污染 负荷解析, 缺乏污染源人湖的物理或生物化学机理, 方法不确定性较大, 系数的确定过程需要开展一定的实 测以验证系数, 且全流域平均化的系数取值, 无法反应流域的空间异质性特点, 在大型水体的应用中需要考 虑不同区域的差异性, 通过实测获取不同区域的排放和人湖系数; 另一方面, 大气沉降、降水携污等是相关 湖泊的主要外部污染源, 底泥释放则是造成部分湖泊污染的重要因素. 在方法的应用过程中, 未来研究要充 分考虑到湖泊自身的特点, 对这些污染的内外源原因予以充分考虑.

\section{4 参考文献}

[ 1 ] Zeng ZX, Zhang H, Shan BQ et al. Analysis of industrial pollution sources of the middle and lower peaches of Hanjiang River basin. Resources and Environment in the Yangtze Basin, 2014, 23(2): 252-259. [曾祉祥, 张洪, 单保庆等. 汉江 中下游流域工业污染源解析. 长江流域资源与环境, 2014, 23(2)：252-259.]

[ 2 ] Cai JB, Sun X, Su LH et al. Investigation and analysis of pollution sources of Gehu Lake. Jiangsu Agricultural Sciences, 2018, 46(5) : 224-227. [蔡金傍, 孙旭, 苏良湖等. 滆湖污染源调查与分析. 江苏农业科学, 2018, 46 (5)： 224-227.]

[ 3 ] Zhou WT, Shao RH, Ma QL et al. Pollution load assessment in the catchment area of Gaozhou Reservoir. Journal of Hydroecology, 2017, 38(3) : 23-31. [ 周文婷, 邵瑞华, 马千里等. 高州水库集水区污染源分布特征及污染负荷研 究. 水生态学杂志, 2017, 38(3) : 23-31.]

[ 4 ] Li CQ, Wang P, Chen B et al. Spatial distribution and pollution source of dissolved metals in the Ganjiang River of Lake Poyang Basin. J Lake Sci, 2018, 30(1) : 139-149. DOI: 10.18307/2018.0114. [李传琼, 王鹏, 陈波等. 鄱阳湖流域 赣江水系溶解态金属元素空间分布特征及污染来源. 湖泊科学, 2018, 30(1): 139-149. ]

[ 5 ] Chen XH, Qian XY, Li XP et al. Long-term trend of eutrophication state of Lake Erhai in 1988-2013 and analyses of its socio-economic drivers. J Lake Sci, 2018, 30(1) : 70-78. DOI: 10.18307/2018.0107. [陈小华, 钱晓雍, 李小平等. 洱 海富营养化时间演变特征 (1988-2013 年) 及社会经济驱动分析. 湖泊科学, 2018, 30(1) : 70-78.]

[ 6 ] Yang GS, Ye M, Yu QM et al. Ecological status and protection suggestions in Houguan Lake area. Yangtze River, 2008, 39(23) : 94-96. [杨国胜,叶闽,余秋梅等. 后官湖地区生态现状及其保护建议. 人民长江, 2008, 39(23) : 94-96.]

[ 7 ] Huang Y, Deng XW, Xu J et al. Water environmental problems and management countermeasures in Lake Houguanhu in Wuhan. Resources and Environment in the Yangtze Basin, 2015, 24(6): 1030-1037. [黄宇, 邓绪伟, 徐军等. 武汉市后 官湖水环境问题和污染防治对策分析. 长江流域资源与环境, 2015, 24(6): 1030-1037.]

[ 8 ] Cai JZ, Fan XP, Huang M et al. Sources analysis of agricultural non-point source pollution in the Three Gorges Reservoir area of Hubei Province China. Environment Science and Pollution Research, 2012, 31(7): 1421-1430. [蔡金洲, 范先 鹏,黄敏等. 湖北省三峡库区农业面源污染解析. 农业环境科学学报, 2012, 31(7): 1421-1430.] 
[ 9 ] Zhang PY, Gou CX, Wu Y et al. Characteristics of rural non-point source pollution in Kaijiang Basin of Sichuan Province. Journal of Agricultural Resources and Environment, 2018, 35(5): 398-404. [张鹏远, 苟楚璇, 巫杨等. 四川凯江流域 农村非点源污染特征分析. 农业资源与环境学报, 2018, 35(5):398-404.]

[10] Xin, Li FM, Xiong QX. Characteristics of agricultural non-point source pollution load in Jiangling County of Hubei Province. Journal of Yangtze University: Natural Science, 2018, 15(18): 41-46. [谭心, 李方敏, 熊勤学. 湖北省江陵县农 业非点源污染负荷特征研究. 长江大学学报：自然学科版, 2018, 15(18): 41-46.]

[11] Liu ZJ, Zhang GC, Yang YH et al. Estimation and spatial distribution of agricultural non-point source pollution loads in Henan Province. Journal of Irrigation and Drainage, 2016, 35(11): 1-6. [刘增进, 张关超, 杨育红等. 河南省农业非 点源污染负荷估算及空间分布研究. 灌溉排水学报, 2016, 35(11) : 1-6.]

[12] Ding J, Li HE, Liu TL et al. Analysis of non-point source pollution characteristics in control sections of upstream and downstream river. Journal of Water Resources and Water Engineering, 2015, 26(6): 26-29. [丁劲, 李怀恩, 刘铁龙等. 河流上下游控制断面非点源污染特征的分析. 水资源与水工程学报, 2015, 26(6) : 26-29.]

[13] Zhang SC, Liu MH. Calculation and analysis of the non-point source pollution of Zhuganhe watershed. Journal of Hydroelectric Engineering, 2006, (5): 51-57. [张思聪, 刘铭环. 竹竿河流域面源污染模拟计算和分析. 水力发电学报, 2006, (5): 51-57.]

[14] Zhao JG, Li HB, Li XY et al. Water pollution characteristics and pollution source of Yongdinghe River in Huailai. Environmental Science and Technology, 2018, 41(S1) : 299-306. [赵建国, 李洪波, 李霄宇等. 永定河怀来段水质污染特 征及污染源解析. 环境科学与技术, 2018, 41 (S1) : 299-306.]

[15] Cai JZ, Fan XP, Huang M et al. Sources analysis of agricultural non-point source pollution in the Three Gorges Reservoir area of Hubei Province, China. Journal of Agri-Environment Science, 2012, 31(7): 1421-1430. [蔡金洲, 范先鹏, 黄 敏等. 湖北省三峡库区农业面源污染解析. 农业环境科学学报, 2012, 31(7)：1421-1430.]

[16] Dong BB, Ma SH, Cao HB et al. Analysis and countermeasures of pollution in Wuliangsuhai Basin. Journal of Anhui Agricultural Sciences, 2011, 39(17) : 10402-10405, 10408. [董蓓蓓, 马淑花, 曹宏斌等. 乌梁素海流域污染现状分析 及防治对策. 安徽农业科学, 2011, 39(17): 10402-10405, 10408.]

[17] Liang X, Zhang X, Liu JF et al. Estimation of permissible pollution bearing capacity and aquaculture pollution load of Changhu Lake. Water Resources Protection, 2015, 31(3): 78-83. [梁秀, 张翔, 刘建峰等. 长湖纳污能力及水产养殖 污染负荷估算. 水资源保护, 2015, 31(3): 78-83.]

[18] Liang Y, Shi WG. An approach of capacity of fish cage culture in the Heilongtan Reservoir. Chongqing Environmental Science, 1997, (6) : 43-46, 49. [梁荫, 施为光. 黑龙滩水库网箱养鱼容量的探讨. 重庆环境科学, 1997, (6): 43$46,49$.

[19] Liu J, Fu B, Wang YK et al. Estimation and evaluation of non-point source pollutants loads in mountainous area of Sichuan. Transactions of the Chinese Society of Agricultural Engineering, 2016, 32(24): 218-225, 316. [刘菊, 傅斌, 王 玉宽等. 四川山区农村面源污染负荷估算与评价. 农业工程学报, 2016, 32(24): 218-225, 316.]

[20] Qiu B, Li PP, Zhong CY et al. Characteristics and spatial distribution of the rural non-point source pollution in Haihe River Basin. China Environmental Science, 2012, 32(3) : 564-570. [邱斌, 李萍萍, 钟晨宇等. 海河流域农村非点源污 染现状及空间特征分析. 中国环境科学, 2012, 32(3): 564-570.]

[21] Zhu M, Wu JX, Li RB. Estimation of non-point source pollution load and environmental risk analysis of rural life in Hai River Basin. Agro-Environment \& Development, 2010, (5): 66-71. [朱梅, 吴敬学, 李瑞波. 海河流域农村生活非点源 污染负荷量估算及环境风险分析. 农业环境与发展, 2010, (5) : 66-71.]

[22] Zhu M, Wu JX, Zhang XS. Pollutants loads of livestock and poultry breeding in Hai Basin, China. Journal of Agro-Environment Science, 2010, (8): 1558-1565. [ 朱梅, 吴敬学, 张希三. 海河流域畜禽养殖污染负荷研究. 农业环境科学 学报,2010,(8):1558-1565.]

[23] Zhu M, Wu JX, Zhang XS. Estimation on non-point source pollution loads of crop farming in Hai Basin. Journal of AgroEnvironment Science, 2010,(10): 1907-1915. [朱梅, 吴敬学, 张希三. 海河流域种植业非点源污染负荷量估算. 农 业环境科学学报, 2010, (10): 1907-1915.]

[24] Shen MM, Su BL, Huang NB et al. Rural domestic pollution around Taihu Lake and estimation of loss rate. Journal of Beijing Normal University: Natural Science, 2013, 49(Z1) : 261-265. [ 申萌萌, 苏保林, 黄宁波等. 太湖周边农村生活污 染调查及人湖系数估算. 北京师范大学学报: 自然科学版, 2013, 49(Z1) : 261-265.] 
[25] Gao Y, Xie YH, Zou DS et al. Changes and driving factors of water surface area for inner lakes in Lake Dongting district in the past 40 years. J Lake Sci, 2019, 31(3) : 755-765. DOI : 10.18307/2019.0314. [ 高耶, 谢永宏, 邹冬生等. 近 40 年 洞庭湖区内湖水面面积变化及其驱动因素. 湖泊科学, 2019, 31(3) : 755-765.]

[26] Jiang Y, Xue LF, Yu HX et al. Change of steam structure in the Nansi Lake Basin during the urbanization process since 1980s. J Lake Sci , 2017, 29 (1) : 135-142. DOI: 10.18307/2017.0115. [江燕, 薛丽芳, 于红学等. 近 30 年来南四湖 流域城市化进程中的水系变化分析. 湖泊科学, 2017, 29(1): 135-142.]

[27] Zheng TT, Zhao ZJ, Zhao XQ et al. Water quality change and humanities driving force in Lake Xingyun Yunnan Province. $J$ Lake Sci, 2018, 30(1) : 79-90. DOI: 10.18307/2018.0108. [郑田甜, 赵祖军, 赵䈗青等. 云南星云湖水质变化及 其人文因素驱动力分析. 湖泊科学, 2018,30 (1): 79-90.]

[28] Wang M, Wang JX, Liu Y et al. Analysis of nitrogen and phosphorus pollution loads from agricultural non-point sources in the Three Gorges Reservoir of Hubei Province from 1991 to 2014. Journal of Agri-Environment Science, 2018, 37 (2) : 294-301. [王萌, 王敬贤, 刘云等. 湖北省三峡库区 1991-2014 年农业非点源氮磷污染负荷分析. 农业环境科学 学报, 2018, 37(2): 294-301.] 